\title{
PODEMOS APRENDER COM A CONCEPÇÃO DE "SAÚDE DA ALMA" DE PLATÃO E COM A DE EPICURO?
}

\author{
CAN WE LEARN FROM DE CONCEPT “HEALTH OF SOUL” BY PLATO AND EPICURUS?
}

Maria Dulce Reis*

\begin{abstract}
RESUMO
A filosofia de Platão e a filosofia de Epicuro florescem em contextos históricos distintos. Por terem abordado a "saúde da alma (psykhé)" em textos que herdamos, buscaremos explicitar o significado filosófico de saúde da alma apresentado por esses dois filósofos. Em diálogos como República, Timeu e As leis, Platão faz uma correlação entre Psicologia, Ética e Política e demonstra que, por meio da educação de cidadãos e governantes, do direcionamento de cada um dos três princípios da psykhé humana (apetitivo, irascível, racional) ao estado de excelência na alma, a virtude pode ser conquistada, o que será designado como saúde tanto para o indivíduo, como para a vida ético-política. Em um de seus textos, Carta a Meneceu, Epicuro propôs uma terapêutica para a saúde da alma, um exercício de tomada de consciência das várias afecções psíquicas para a aquisição do autodomínio e da boa capacidade de agir. Em ambos os filósofos, o exercício do discernimento sobre as causas (racionais e irracionais) de nossas escolhas é condição para a conquista de um estado de saúde, equilíbrio, resistência. Pensar com os gregos, neste momento histórico de pandemia e crise, é identificar como reagimos diante de tal realidade e como podemos agir diante dela.
\end{abstract}

PALAVRAS-CHAVE: Platão; Epicuro; Filosofia antiga; psicologia; saúde; educação.

\section{ABSTRACT}

Plato's philosophy and Epicurus' philosophy emerge during different historical contexts. Due to they have dealt with "soul health (psykhé)" in texts we have inherited, we will try to explain the philosophical meaning of the soul's health presented by both philosophers. In the dialogues as Republic, Timaeus, and The Laws, Plato makes a correlation between Psychology, Ethics, and Politics and demonstrates that, through the citizens and government's education, the direction of each of the three principles of human psykhé (appetitive, irascible, rational) to the state of excellence in the soul, virtue can be achieved, which will be designated as health for both the individual and ethical-political life. In one of his texts, Letter to Meneceu, Epicurus proposed therapy for the soul's health, an exercise of becoming aware of the psychic reactions for the achievement of self-mastery and the good ability to act. For both Philosophers, the exercise of discernment about the causes (rational and irrational) of our choices is a condition for a state of health achievement, balance, resistance. To think like the Greeks, in this historical moment of pandemic and crisis, is to identify how we react in front of this reality and how we can act to face it.

KEYWORDS: Plato; Epicurus; Ancient philosophy; psychology; health; education.

\footnotetext{
* Doutora em Filosofia. Professora do Departamento de Filosofia da PUC Minas. E-mail: mariadulcereis@pucminas.br.
} 


\section{INTRODUÇÃO}

Encontramo-nos em um momento histórico ímpar, todas as nações convivendo, nos anos de 2020 e 2021, com a pandemia pelo coronavírus SARS-CoV-2, que trouxe à tona inúmeros conflitos e contradições de nosso tempo e inúmeras consequências em vários âmbitos (social, político, econômico, pedagógico, sanitário, dentre outros). O exercício da Filosofia não pode se furtar a buscar dar sentido a essas crises, como já o fez desde o período de seu surgimento, com os chamados Filósofos Antigos. Nesse momento dramático, de sofrimento para toda a humanidade, refletirmos sobre os vários significados possíveis para saúde e doença nos parece algo necessário e fértil. Ainda que levadas em consideração as diferenças de época e local, podemos buscar alguns desses significados de saúde e doença na origem do pensamento filosófico. Tal nos parece ser uma tarefa enriquecedora para o momento atual, pensar com os gregos, mesmo porque encontra-se na Filosofia Grega Antiga não apenas nosso passado, mas nossa identidade ${ }^{1}$.

\section{A CONCEPÇÃO DE “SAÚdE DA ALMA” DE PLATÃO E A DE EPICURO}

Amplo é o período considerado como aquele da Filosofia Antiga, abrange a produção filosófica desde o século VI a. C. até o século VI d. C. Platão e Epicuro encontram-se em momentos diferentes desse período, e seus textos foram elaborados em (e respondem a) contextos históricos distintos, a Atenas de fins do século V a. C. ao século IV a. C. e aquela de fins do século IV ao século III a. C., respectivamente. Por terem abordado a "saúde da alma (psykhé)" em textos que herdamos, vamos buscar explicitar o significado filosófico de "saúde da alma" apresentado por esses dois filósofos, cientes de que Epicuro não é considerado um "seguidor" da filosofia platônica, sendo, contudo, um filósofo que retoma a problemática socrática do "viver bem" e do cuidado com a alma. Ambos tratam de tal noção no contexto de doutrinas que abrangem o todo corpo/alma. Como vamos nos deter ao aspecto da "saúde da alma", quanto a um aprofundamento do aspecto da "saúde do corpo" remetemos o leitor a outros estudos $^{2}$. Os filósofos respondem a problemáticas de seu tempo. Ainda assim, os aspectos estruturais do modo de ser humano que eles identificam e a profundidade de seus textos nos

\footnotetext{
${ }^{1}$ Como nos aponta Brandão (2002, p. 35) que nos convida a "pensar com os gregos".

${ }^{2}$ Eijk (2009); Silva (2009).
} 
Artigo do dossiê: Podemos aprender com a concepção de "saúde da alma" de Platão e com a de Epicuro?

fazem pensar sobre o ser humano no sentido universal, e nos fazem pensar a "saúde da alma" em nosso momento atual. Vejamos diretamente algumas passagens de seus textos.

\section{SAÚDE DA PSYKHÉ EM PLATÃO}

A relação entre a medicina hipocrática e alguns termos e concepções presentes nos textos de Platão (nascido em Atenas, em 428 a. C.) tem sido objeto de estudos recentes, como nos aponta Frias (2005). Segundo seu estudo, percebe-se um uso similar de termos como eîdos, idéa, isonomía, monarkhía, períodos, aísthesis, phýsis, bem como de concepções: relação entre parte e todo, entre micro e macrocosmo. Segundo Jaeger (1989), Platão faz uma aplicação de conceitos de origem médica à sua filosofia (como os de katà phýsin e parà phýsin e o de héxis ou como o de plenitude e vazio), assim como de termos médicos (como os termos eíde psykhés e thymoeidés). Para além da discussão a respeito de uma influência mútua entre Medicina e Filosofia, tem sido reconhecida a originalidade de Platão em ter atribuído causalidades psíquicas (e não corpóreas) às então denominadas "doenças da psykhê", sobretudo no texto do Timeu. Estudiosos recentes como Ivan Frias (2005) e Philip Eijk (2009) reconhecem a importância das concepções de saúde e doença da psykhé desenvolvidas por Platão em seus diálogos fílosóficos ${ }^{3}$.

Inúmeras são as passagens, nos diálogos platônicos que trazem o termo "saúde" e tal levantamento de ocorrências ultrapassa os limites do presente texto. Aqui, vamos chamar a atenção para algumas passagens que mostram a relação entre "saúde da alma" e "virtude", que apontam a importância do domínio de si (estado de relação saudável entre as afecções irracionais e racionais da própria alma) como condição para o bem viver. Vamos traduzir o termo psykhé por "alma”, por ser a tradução frequente, significando (em Platão e em Epicuro) um amplo conjunto de capacidades do todo (alma/corpo) humano vivo: ter apetites, desejos,

\footnotetext{
${ }^{3}$ Respectivamente: "Na obra de Platão, há uma reflexão original sobre a relação corpo-alma tanto do ponto de vista estritamente filosófico quanto daquele relacionado aos estados de saúde e doença. Na medicina hipocrática... a doença é uma condição relativa ao corpo. [...] Ao atribuir à alma a hegemonia sobre o corpo, ele [Platão] está, ao mesmo tempo, imputando à alma a causa da doença do corpo e admitindo, por consequência, a doença da alma." (FRIAS, 2005, p. 79-80). "É só quando chegamos ao Timeu de Platão que 'doenças da alma' são diferenciadas de doenças do corpo (86b2 ss.). E isso não é surpreendente se consideramos a visão geral de Platão sobre a relação entre corpo e alma. Nem deve surpreender que a enfermidade mental seja atribuída à má administração do corpo ou que a saúde mental seja uma questão de observar um regime no qual o corpo e sua influência sobre a alma, através da paixão e do desejo, sejam mantidos sob controle estrito. A saúde mental é uma questão de moralidade, sustentada por um estilo de vida frugal e guiada pela razão - se não a do próprio indivíduo, a razão do líder da cidade." (EIJK, 2009, p. 24).
} 
sentimentos, conhecer, opinar, agir. A partir de estudos que já realizamos em outros momentos, a respeito da correlação entre Psicologia, Ética e Política em três dos diálogos escritos por Platão, a República, o Timeu e as Leis ${ }^{4}$, vamos levar em conta algumas passagens nas quais a saúde do indivíduo é identificada como estado de equilíbrio da psykhé, de suas afecções (ou seja, de como ela é afetada, produzindo impulsos, sentimentos, opiniões) que, por sua vez, produzem as ações humanas (saudáveis ou não). A conquista desse estado de equilíbrio é apresentada como condição necessária para a resistência diante das adversidades da vida.

No livro IV da República, o Sócrates platônico em diálogo com seus interlocutores, analisa qual seria a natureza (no sentido de estrutura de funcionamento) da psykhé humana, reconhecendo seus três princípios de ação como o racional, o irascível, o apetitivo, diferentes em suas demandas e competências, passíveis de serem direcionados para uma configuração virtuosa, sendo essa nova configuração chamada de "saúde" da alma. Ao elemento apetitivo (impulsos que buscam satisfação imediata, dos mais tirânicos aos mais domésticos) cabe a preservação da vida, podendo sua energia ser direcionada a finalidades benéficas. Ao elemento irascível (marcado pela afecção da ira, da agressividade, mas também constituído por outras afetações como o medo, a tristeza etc.) cabe o combater, por finalidades que podem ser racionais ou não. Ao elemento racional (atividades de raciocinar, julgar, escolher etc.) cabe discernir e governar o todo da psykhé, em uma alma devidamente formada e educada.

No decorrer de toda a República, Sócrates traça como os três elementos da alma deveriam ser educados para que o todo da psykhé conquiste um estado de maior aprimoramento possível, para que desenvolva sua excelência (areté), virtude. Após colocar em palavras o que corresponderia à posse da virtude da justiça na psykhé humana e o seu reflexo na cidade (República 443c-d), a justiça como uma atividade interna, que o homem exerce sobre si mesmo e para si mesmo governando ele mesmo a si próprio (árkanta autòn autôu), ordenando-se, reunindo harmoniosamente os três elementos distintos da alma em uma relação de unidade, Sócrates afirma que a virtude seria uma espécie de "saúde, beleza e bem-estar da alma" (República 444d-e) e sua ausência corresponderia à doença, "uma enfermidade, feiura e debilidade" da psykhé. O não aprimoramento das partes irracionais e racional da alma humana é identificado com o estado de doença da/na alma.

\footnotetext{
${ }^{4}$ Reis (2009); Reis (2010).
} 
Artigo do dossiê: Podemos aprender com a concepção de "saúde da alma" de Platão e com a de Epicuro?

Se saúde equivale a um estado de excelência a ser conquistado pelo ser humano em sua relação com os demais, a aquisição da posse de tal estado de excelência do todo corpo/alma requer um projeto de educação dos princípios ou partes da psykhé.

Na República, a educação da alma é proposta por meio de várias etapas, que vão da ginástica para o corpo e da arte das musas para a alma (para a conquista de um estado de apaziguamento dos impulsos da parte apetitiva da alma e da parte irascível, resistência emocional, além da resistência física) até a prática da Filosofia. Por tal meio e também pela introjeção das leis, ocorre a educação do gênero irascível da alma, com todo seu leque de afecções (jogos em comum, leis, artes que sejam capazes de promover uma moderação da ira, da tristeza, do medo etc.). Quanto à educação da parte racional da alma, ela ocorre por meio do estudo de várias ciências e, posteriormente, por meio da atividade da dialética (exercício de Filosofia). O exercício do diálogo filosófico permitiria a passagem de um raciocínio baseado nos dados sensíveis a um raciocínio que alcança as verdadeiras causas de suas determinações sensíveis: as Formas inteligíveis (ou Ideias, independentes do sensível e do ser humano). Tal processo árduo de educação do gênero racional da alma humana recebe uma argumentação demonstrativa na República, bem como um recurso mítico, as famosas imagens do diagrama da linha (livro VI) e da caverna (livro VII).

O paradigma da alma filosófica, em contraposição à alma tirânica, traçado no decorrer de toda a República, demonstra teoricamente que o estado de alma saudável equivale àquele em que o elemento racional da alma, bem educado pela dialética, exerce poder sobre o todo da alma, no jogo de forças políticas internas à psykhé, isto é, no conflito entre demandas distintas, aquelas do apetitivo, do irascível, do racional. A referida passagem sobre a conquista da virtude da justiça pela alma, como estado de unidade entre elementos distintos (República 443c-d) é um paradigma a ser buscado por cidadãos e governantes para que suas ações possam se realizar de um modo também virtuoso, sábio. Sendo assim, a conquista de estados internos de virtude é condição para uma vida política saudável, virtuosa, no plano maior da cidade.

No texto das Leis, último diálogo escrito por Platão, o projeto educativo platônico é semelhante e direciona-se sobretudo à conquista da resistência emocional e do estado interno de paz, em oposição ao estado de guerra interna (Leis 626e), em uma cidade voltada para a paz.

Nas Leis, Platão realiza uma extensa e profunda análise sobre a ação má ${ }^{5}$ e propõe, para que a alma injusta seja reeducada (curada), que a lei use de meios capazes de agir sobre a parte

\footnotetext{
${ }^{5}$ Reis (2010), capítulos 3 e 4.
} 
da alma que ainda não conquistou seu estado de virtude, assim causadora de condutas injustas ou más. A educação para a posse da virtude é traçada, no livro I, por meio de uma imagem (644c-645c), a dos seres vivos (dzóon) como marionetes dos deuses, guiados por "fios" de diversas espécies, que são as afecções (páthe), como o prazer e o sofrimento, o medo e a confiança. Essas afecções o enredam e, se são contrárias umas às outras, o arrastam para ações contrárias, "sob a linha divisória entre a virtude e o vício" (644e). Capaz de orientar as afecções, seguindo algumas e resistindo a outras, está o $\log o s$, o fio condutor sagrado do raciocínio, flexível, com o qual se deve colaborar "para assegurar que a raça áurea dentro de nós possa derrotar as outras raças" (645b). O poder de domínio sobre as diversas afecções é possível e considerado próprio da razão bem educada pela Filosofia.

O modo como se daria a educação da alma para a virtude é trabalhado em vários momentos do texto das Leis, sobretudo no livro VII, que detalha a educação desde a gestação até a velhice. Não vamos nos ater em cada passo dessa educação da alma, devemos ressaltar que ela propõe um apaziguamento de seus temores, medos, apetites, sofrimentos e aflições (790e), desde o uso da música e da dança, a prática de jogos em comum, a contenção de impulsos e o seguimento a leis, possibilitando o surgimento de sentimentos como a filantropia (808d), até o ensino das ciências da época, sendo, na sequência, o exercício da Filosofia considerado importante sobretudo àqueles que comporão o chamado "Conselho Noturno" (818a-969b) que terão a tarefa de adequar as leis à promoção da virtude, instruir os jovens futuros governantes e cuidar da alma daqueles que necessitam ser persuadidos por argumentos, de modo que a vida política seja regida pela medida, temperança, inteligência e pelo discernimento (689a-712a).

Na obra Timeu, não encontramos um projeto educativo propriamente, mas, tratando-se da cosmologia de Platão, encontramos o "lugar" do homem no contexto maior da vida do cosmos e de princípios que teriam existência independente do cosmos. A concepção de saúde como estado interno de virtude, de uma relação de unidade justa entre elementos distintos encontra-se presente, como nos demais textos de Platão. Na narrativa mítica do Timeu, a constante busca de equilíbrio do todo corpo/alma humano por meio de sua devida nutrição é reafirmada, como na passagem Timeu 44c: "com a nutrição de uma educação correta (orthé trophè paideúseos), o ser humano torna-se completamente são (hygiés) e inteiro (holókleros)", sendo o elemento racional da alma considerado aquele capaz de deliberar bem sobre o que é comum ao todo (70a). 
Artigo do dossiê: Podemos aprender com a concepção de "saúde da alma" de Platão e com a de Epicuro?

No Timeu, são analisadas as doenças da psykhé, o que elas constituem ${ }^{6}$. Platão aborda as doenças da psykhé como marcadas pela desrazão, manifesta seja na loucura (manía) ou na ignorância (amathía). Afirma que as mais graves doenças da alma (86b3-7) decorrem dos prazeres excessivos e dos sofrimentos excessivos, traçando seus sintomas e reconhecendo, como causas inconsentidas das doenças da psykhé, tanto a má educação da alma e uma má disposição do corpo, como - vale destacar - a ação de maus discursos e maus regimes políticos nos homens cujas constituições são más (86e1; 87b4). Platão reafirma que a busca de equilíbrio entre elementos distintos, por meio de uma reta educação de seus membros, deve ser construída e conquistada, seja no interior da alma humana, seja no interior de um regime político.

Podemos identificar, em tais textos de Platão, que, por meio da educação, do direcionamento ao estado de excelência de cada um dos três princípios da alma humana, o estado de excelência da psykhé — a virtude - pode ser conquistado, o que será designado como "saúde" tanto para o indivíduo, como para a cidade. Ao mostrar a natureza e a estrutura da psykhé e das relações sociais construídas a partir dela, Platão busca o aprimoramento das almas e das relações ético-políticas, tanto o ser capaz de agir com justiça, como de defender-se contra a injustiça, preservando um estado de saúde e de harmonia na alma e na cidade. Veremos que Epicuro já não tem em vista o aprimoramento das relações ético-políticas, contudo sua doutrina propõe o autodomínio e a capacitação da alma humana para a resistência diante das adversidades.

\section{SAÚDE DA PSYKHÉ EM EPICURO}

Epicuro (nascido em Samos em 341 a. C.) distancia-se de Platão por encontrar-se em um contexto histórico posterior, característico da Grécia da segunda metade do século IV à primeira metade do século III a. C. e da chamada Filosofia Helenística ${ }^{7}$. Epicuro funda em Atenas, em fins do séc. IV a. C. uma escola filosófica situada longe da vida pública, próximo ao campo, daí ser chamada Jardim; e sua doutrina, epicurismo. Tal escola se extingue na segunda metade do século I a. C.. Epicuro propõe uma doutrina filosófica a respeito da sabedoria prática, de como viver sabiamente e prazerosamente.

\footnotetext{
${ }^{6}$ Reis (2010), capítulo 2.

${ }^{7}$ Sobre a Filosofia Helenística há uma ampla bibliografia. Para uma introdução, sugerimos Chauí (2010). Sobre a ética Helenística e, em particular, a ética epicurista, indicamos Vaz (1999, p. 132-142).
} 
De modo distinto de Platão, Epicuro nega a existência de realidades incorpóreas, valoriza as sensações e a vida natural, daí um afastar-se da vida política, bastando as relações de amizade. Nesse sentido, considera como bens o prazer (distinto de incontinência) e a ausência de perturbações da alma. O exercício da sabedoria está em avaliar e escolher o que vem a ser útil ou danoso, o que vem a ser um bem ou um mal para si próprio, suprimindo-se sofrimentos ou perturbações, permanecendo sereno em meio aos tormentos da vida, satisfazendo desejos necessários e rejeitando prazeres danosos, bastando-se (autarquia). O epicurismo retoma a importância dada pela tradição socrática aos problemas éticos e à saúde da alma, reafirma a Filosofia como exercício de libertação das paixões da alma, esta sendo material e homogênea ao corpo.

Como fonte do pensamento de Epicuro, temos: Carta a Heródoto; Carta a Meneceu; Carta a Pitócles; uma coleção de aforismos (Máximas Soberanas), fragmentos do tratado "Sobre a Natureza"; "Sentenças Capitais". As "Sentenças" e a Carta a Meneceu são fontes para o conhecimento da ética de Epicuro.

Tratemos da Carta a Meneceu, dirigida a um de seus discípulos, buscando explicitar a concepção de saúde da pskyhé, nela abordada. Em cada passagem da carta que vamos mencionar, seguiremos a edição bilingue da Editora UNESP, 2002, indicando a página de sua ocorrência nessa edição e com destaque nosso a termos significativos das passagens.

Já no início da Carta a Meneceu, Epicuro (2002, p. 45) convida seu discípulo a alcançar a saúde da psykhé, por meio do exercício da Filosofia, propondo condutas para uma terapêutica da alma. Podemos identificar nessa terapêutica um exercício de tomada de consciência das afecções psíquicas e de opiniões falsas, de modo a assim "examinar as causas de toda escolha e de toda rejeição", condição para o autodomínio e a boa capacidade de agir (eudaimonía).

A leitura atenta às passagens da Carta a Meneceu nos mostra a concepção de saúde da alma como resultado do reconhecimento da natureza das reações ou afecções psíquicas (que hoje costumamos chamar de sentimentos, nelas incluindo-se afecções racionais, as opiniões). Tal reconhecimento permite que seja possível não se deixar dominar por elas e, sim, fazer escolhas sábias.

Pode-se observar tal caminho para a saúde apresentado por Epicuro (2002, p. 21-22) já nas primeiras passagens da Carta a Meneceu, passagens sobre as opiniões ilusórias dos homens a respeito dos deuses e a respeito da morte, capazes de gerar uma perturbação na alma: “[...] a filosofia é útil para [...] poder envelhecer sem sentir medo das coisas que estão por vir [...]”; “[...] os juízos do povo a respeito dos deuses não se baseiam em noções inatas, mas em opiniões 
Artigo do dossiê: Podemos aprender com a concepção de "saúde da alma" de Platão e com a de Epicuro?

falsas. Daí a crença de que eles causam os maiores malefícios aos maus e os maiores benefícios aos bons." (p. 25); “[...] todo bem e todo mal residem nas sensações, e a morte é justamente a privação das sensações. A consciência clara de que a morte não significa nada para nós proporciona a fruição da vida efêmera [...] (p. 27); [...] É tolo, portanto, quem diz ter medo da morte, não porque a chegada desta lhe trará sofrimento, mas porque $o$ aflige a própria espera [...]" (p. 29).

A Carta a Meneceu prossegue tratando dos apetites humanos. Conhecer diferenças entre os apetites é a condição para atender a alguns deles, mas não a todos. Na edição que seguimos, o termo epithymia é traduzido por "desejo": "dentre os desejos, há os que são naturais e os que são inúteis [...] E o conhecimento seguro dos desejos leva a direcionar toda escolha e toda recusa para a saúde do corpo e a serenidade do espírito (psykhês ataraxían), visto que esta é a finalidade da vida feliz [...]" (p. 35); "Uma vez que tenhamos atingido esse estado, toda a tempestade da alma se aplaca [...]" (p. 35); "só sentimos necessidade do prazer quando sofremos pela sua ausência; ao contrário, quando não sofremos, essa necessidade não se faz sentir" (p. 37).

Devemos observar que o texto segue com um aprofundamento do caráter do prazer e com um convite à reflexão sobre seus efeitos: "o prazer é o início e o fim de uma vida feliz. Com efeito, nós o identificamos como o bem primeiro e inerente ao ser humano, em razão dele praticamos toda escolha e toda recusa [...]" (p. 37); "Embora o prazer seja nosso bem primeiro e inato, nem por isso escolhemos qualquer prazer: há ocasiões em que evitamos muitos prazeres, quando deles nos advêm efeitos o mais das vezes desagradáveis [...]" (p. 37); "[...] nem todos [os prazeres] são escolhidos, do mesmo modo, toda dor é um mal, mas nem todas devem ser sempre evitadas" (p. 39).

A consciência do prazer como um bem cujos efeitos devem ser objeto de análise, (considerando-se prazer também a ausência de perturbações na alma) afasta opiniões enganosas e capacita a alma para escolhas sábias: "Convém, portanto, avaliar todos os prazeres e sofrimentos de acordo com o critério dos benefícios e danos. Há ocasiões em que utilizamos um bem como se fosse um mal e, ao contrário, um mal como se fosse um bem." (p. 39); "Quando então dizemos que o fim último é o prazer, não nos referimos aos prazeres dos intemperantes [...] mas ao prazer que é ausência de sofrimentos físicos e de perturbações da alma" (p. 43).

Consideramos importante observar que, para Epicuro, o homem sábio deve reconhecer como bens o discernimento (phrónesis) e a autossuficiência (autarkheia), estados de alma que 
permitem enfrentar os desafios da vida, com resistência emocional (e não medo) e com sabedoria prática (e não opiniões falsas) ${ }^{8}$ : "Consideramos ainda a autossuficiência um grande bem [...] Habituar-se às coisas simples [...] não só é conveniente para a saúde, como ainda proporciona ao homem os meios para enfrentar corajosamente as adversidades da vida [...] (p. 41); "[a autossuficiência] nos prepara para enfrentar sem temor as vicissitudes da sorte" (p. 43); "De todas essas coisas, a prudência (phrónesis) é o princípio e o supremo bem [...] é dela que originaram todas as demais virtudes; é ela que nos ensina que não existe vida feliz sem prudência, beleza e justiça" (p. 45). Portanto, o prazer é um bem e o exercício do discernimento (phrónesis) é reconhecido como o supremo bem, pois é o exercício do pensar, do avaliar causas e efeitos, prazeres e sofrimentos, benefícios e danos, que permite reconhecer boas escolhas.

É notável percebermos, nessas passagens, que o caminho para a saúde da psykhé, para a vida sábia, conta com o desenvolvimento de uma harmonia interna do todo da alma, e não com uma atividade exclusivamente racional, muito menos se confunde com a saciedade de impulsos irracionais. O ser senhor de si, o autodomínio, envolve a alma como um todo, inclusive o todo corpo/alma. A conquista da virtude do discernimento envolve o todo e produz efeitos saudáveis sobre o todo. É esse aspecto da concepção de saúde em Epicuro que nos parece próximo à concepção de saúde do Sócrates platônico, ainda que em contextos históricos e concepções filosóficas distintas.

\section{CONSIDERAÇÕES FINAIS}

$\mathrm{Na}$ introdução do presente texto, enunciamos uma pergunta: podemos aprender com a concepção de "saúde da alma" de Platão e com a de Epicuro? Essa pergunta, mobilizada no contexto histórico em que estamos vivendo, teve lugar por dois motivos e propósitos: primeiro, o desejo de mostrar uma inter-relação possível entre o exercício da Filosofia e a conquista de um estado de "saúde da alma"; segundo, o da urgência de buscar sentido, por meio do exercício filosófico, para o momento histórico que estamos vivendo, o da pandemia do Coronavírus, que, por sua vez, colocou em evidência inúmeros outros problemas a serem tratados com profundidade, dentre eles os conflitos de valores no interior das configurações políticas de cada

\footnotetext{
${ }^{8}$ Epicuro parece chamar a atenção para a autorresponsabilidade humana pelas suas escolhas e ações: “[...] será que pode existir alguém mais feliz do que o sábio que [...] nega o destino, apresentado por alguns como o senhor de tudo, já que as coisas acontecem ou por necessidade, ou por acaso, ou por vontade nossa (par'hemâs); e que a necessidade é incoercível, o acaso, instável, enquanto nossa vontade é livre (tò dé par'hemâs adéspoton) [...]”' (p. 47-49).
} 
Artigo do dossiê: Podemos aprender com a concepção de "saúde da alma" de Platão e com a de Epicuro?

nação e nas relações político-econômicas entre nações. Soma-se a essa situação, no caso de nosso país, a situação dramática de descaso com a saúde pública mantida pelo Governo. Estamos todos, portanto, em busca de sentido, de equilíbrio e de alternativas para a superação dessa realidade política. É nesse sentido que consideramos que podemos aprender com as concepções de "saúde da alma" de Platão e de Epicuro.

Com o caminho para a sabedoria, o quádruplo remédio, proposto por Epicuro, podemos aprender a importância da tomada de consciência sobre nossas próprias afecções (sensações, emoções, sentimentos, impulsos, opiniões falsas) para que não nos deixemos levar por elas, mas, tratando-as como sinais de nosso modo de reagir diante da realidade, possamos vir a ser "senhor" delas, ter autodomínio, resistência emocional e discernimento (phrónesis) para agir. Esse caminho, possivelmente inspirado pela filosofia socrática, também foi tematizado pela filosofia de Platão, que mais de perto ainda teria sido afetada pelos ensinamentos de Sócrates.

Em ambos os filósofos, o exercício do discernimento sobre as causas (racionais e irracionais) de nossas escolhas é condição para a conquista de um estado de saúde, equilíbrio, resistência, autodomínio, autarquia, sabedoria. No entanto, deve-se ressaltar que, se Epicuro deixa de lado o campo conflituoso da vida política, as teorias de Platão, expostas em seus diversos diálogos, demonstram o quanto estão entrelaçados os campos do indivíduo e da cidade, da "saúde da alma" e da "saúde da vida política", como são retroalimentadas: vida política saudável, justa, e vida psíquica saudável, virtuosa. Não estamos propondo um retorno a regimes políticos propostos ou mesmo vivenciados pelos filósofos que abordamos. Mas nos parece saudável revermos o significado originário do exercício ativo da cidadania, a relação dialética entre indivíduo e cidade, o pressuposto lógico de que o caráter de uma cidade surge a partir dos indivíduos particulares (República 435e).

Platão propõe uma educação das partes irracionais e racional das almas (de cidadãos e de governantes) para que conquistem um regime político interno justo, como condição para uma vida política justa no campo maior da cidade - conflituosa, mas passível de se dirigir a um estado justo (República), pacífico (Leis), saudável (Timeu). Para não nos repetirmos, nessas considerações finais, quanto ao modo como ocorre essa articulação entre indivíduo e cidade, entre Psicologia, Ética e Política, vale lembrar uma feliz metáfora criada por Platão, a imagem da caverna (no livro VII da República), que dá margem a várias interpretações possíveis e que articula diferentes graus de conhecimento, graus de ser, graus de ação ética. A saída do fundo da caverna em direção à luz é uma escolha e depende do desejo, da oportunidade e do esforço de cada um (cidadãos e governantes). 
Perceber o que há de ilusório em si mesmo, resistir, ir além de afecções (como certos desejos, poderes, crenças sobre o bem), buscar um conhecimento aprofundado sobre si mesmo e sobre o outro, buscar desenvolver o melhor de si e o melhor do outro, diferenciar opiniões falsas e opinião verdadeira, reconhecer que o diálogo que vai às raízes (o diálogo filosófico) é necessário para uma vida política justa, isto é, para a realização da justiça na História, são grandes legados que nos deixa Platão e um grande aprendizado para nossa época. Platão mostra que temos, dentro de nós mesmos, querendo ou não, um certo regime político, uma constante tensão entre diferentes potências. Sendo assim, cuidar de sua própria alma, autoconhecimento e autodomínio mostram-se como condições para uma vida política externa saudável e pacífica.

Pensar com os gregos, nesse momento histórico de pandemia e crise, é identificar como reagimos diante de tal realidade e como podemos agir diante dela. É acolher como fomos afetados: nossos sentimentos de angústia, medo, dor profunda, tristeza, nossos apetites, dos mais tirânicos aos mais saudáveis, nossos desejos de vida, proteção, manifestação. É reconhecer nossas opiniões, das mais ilusórias às mais fundamentadas pela lógica, ouvir nossas expectativas, das desilusões às esperanças. É tomar consciência do que estamos a criar, dentro e fora de nós. É sair da passividade política, fazer a nossa parte, e há muito a fazer.

Pensar com os gregos é abandonar a visão estanque de que razão e irracionalidade humanas seriam opostas e, profundamente, entendê-las como elementos de um mesmo todo, faces de uma mesma "mistura": o ser humano. Nesse sentido, é concentrar nossas ações no autoconhecimento (o respeito a si mesmo), na consciência da alteridade (o respeito ao outro), na promoção da filantropia (o amor aos seres humanos e à vida do cosmo), na vida política saudável (o exercício do diálogo e da ética como condições para a boa política e o bem viver).

\section{REFERÊNCIAS}

BRANDÃO, Jacyntho Lins. Nós e os gregos. In: FERREIRA, Amauri Carlos et al. Os gregos. Organização de Haroldo Marques. Belo Horizonte: Autêntica: PUC Minas, 2002, p. 29-44. (Coleção Convite ao Pensar).

CHAUÍ, Marilena. A filosofia helenística. São Paulo: Cia das Letras, 2010. V. II. (Col. Introdução à História da Filosofia Antiga).

EIJK, Philip Van Der. Os conceitos de saúde mental na medicina e na filosofia gregas dos séculos V e IV a.C. (com um breve panorama da Antiguidade tardia). Tradução de Marcelo Pimenta Marques. In: PEIXOTO, Miriam Campolina Diniz (org.) A saúde dos antigos: reflexões gregas e romanas. São Paulo: Loyola, 2009. p. 11-32. 
EPICURO. Sobre a felicidade. Carta a Meneceu. (Bilingue) Tradução e apresentação de Álvaro Lorencini e Enzo Del Carratore. São Paulo: Editora UNESP, 2002.

FRIAS, Ivan. Doença do corpo, doença da alma: medicina e filosofia na Grécia Clássica. São Paulo: Loyola, 2005.

JAEGER, Werner. Paideia. 2. ed. São Paulo: Martins Fontes, 1989.

PLATÃO. As leis. Tradução e Com. de Edson Bini. Bauru, SP: EDIPRO, 1999.

PLATÃO. República. Tradução de M. H. da Rocha Pereira. 7. ed. Lisboa: Fundação Calouste Goubenkian, 1993.

PLATÃO. Timeu. Tradução de C. A. Nunes. Belém: Ed. Universidade Federal do Pará, 1986.

PLATÃO. Platonis Opera - T.IV Tetralogiam VIII continens [insunt Politia, Timaeo et Critia], recognovit brevique adnotatione critica instruxit Ioannes Burnet. Oxford: Oxford Clarendon Press, 1902. T.V Tetralogiam IX continens [insunt Minos, Leges, Epinomis, Epistulae, Definitiones et spuria], recognovit brevique adnotatione critica instruxit Ioannes Burnet. Oxford: Oxford Clarendon Press, 1907.

REIS, Maria Dulce. Psicologia, ética e política. A tripartição da psykhé na República de Platão. São Paulo: Loyola, 2009. (Coleção FAJE).

REIS, Maria Dulce. Virtude e vício: tripartição e unidade da psykhé no Timeu e nas Leis de Platão. Rio de Janeiro: Editora 7Letras, 2010.

SILVA, Markus Figueira da. Sabedoria e saúde do corpo em Epicuro. In: In: PEIXOTO, Miriam C. D. (org.) A saúde dos antigos: reflexões gregas e romanas. São Paulo: Loyola, 2009. p. 153162.

VAZ, Henrique Cláudio de Lima. Escritos de filosofia IV. Introdução à ética filosófica 1. São Paulo: Loyola, 1999. (Coleção Filosofia). 